\title{
A Study of a DC/AC Conversion Structure for Photovoltaic System Connected to the Grid with Active and Reactive Power Control
}

\author{
Houda Brahmi $\mathbb{D}^{1}$ and Rachid Dhifaoui ${ }^{2}$ \\ ${ }^{1}$ University Tunis El Manar, Higher Institute of Medicals Technologies of Tunis (ISTMT), Rue Zouhair Essafi, 1006 Tunis, \\ Unit of Research ERCO-INSAT, Tunisia \\ ${ }^{2}$ Unit of Research (ERCO), INSAT, Centre Urbain Nord, B.P. N676, 1080 Tunis Cedex, Tunisia \\ Correspondence should be addressed to Houda Brahmi; houda.brahmi@istmt.utm.tn
}

Received 18 March 2021; Revised 18 June 2021; Accepted 26 June 2021; Published 7 July 2021

Academic Editor: Chun Wei

Copyright (C) 2021 Houda Brahmi and Rachid Dhifaoui. This is an open access article distributed under the Creative Commons Attribution License, which permits unrestricted use, distribution, and reproduction in any medium, provided the original work is properly cited.

\begin{abstract}
DC/AC conversion of photovoltaic energy is in great demand for AC applications; the supply of electrical machines and transfer energy to the distribution network is a typical case. This work is realized in this context and presents a new structure for the transfer of photovoltaic energy to the electricity grid. This structure is based on a push-pull converter connected to a three-phase $\mathrm{DC} / \mathrm{AC}$ inverter. In particular, a great interest is focused on the steady operating conditions of energy transfer. The study also develops the limits and the feasibility of the PV energy transfer to the grid of the proposed structure. Injecting photovoltaic energy into the grid with maximum active power and zero reactive power is also considered for the dynamic regime. Support simulations are carried out to validate the proposed control strategy.
\end{abstract}

\section{Introduction}

Renewable energies are inexhaustible and clean and have the additional advantage of complementing each other. This favours and encourages their integration in the AC grid. Among these sources, photovoltaic solar energy offers a very promising alternative [1-5]. It is experiencing a wide development, favoured by the awareness of governments and other organizations seriously calling to preserve the environment.

Relatively for a long time, photovoltaic solar energy was used as a power source only for certain loads, such as satellites and/or rural areas situated far from conventional electricity transmission lines [6-9]. Nowadays, from the environmental concern of modern society, economical point of view, and technology advances, the interest in solar energy and associated conversion systems has emerged as good future solution. Furthermore, photovoltaic solar energy has the greatest potential for use in various ways. Due to its modular nature, it can be used in the country side and in the city, in small and large places [10-12].
Basically, there are two types of solar energy applications: isolated systems and grid connected systems [13, 14]. For the first case, we found a lot of applications: isolated and independent houses or equipment, rural power plants, telecommunication networks, water pumping, lighting systems, computers or cell phones, cameras, calculators, etc. Surely, photovoltaic solar energy can offer a more significant contribution in many countries where electrification levels are close to saturation [15-17]. Furthermore, many countries in Europe and Africa have great chance to produce photovoltaic energy in very high quantities. This is why the second case dealing with connexion of solar photovoltaic energy to the electricity grid shows a high growing rate during the last decades. At present, the governments of various European countries, Japan and the United States, among others, are promoting economic incentives for renewable energies to try to cope with climate change [18-20]. In this sense, there are special credits to finance photovoltaic installations for connection to the grid and remuneration per $\mathrm{kWh}$ sold to the electricity company. 
To generate photovoltaic solar electricity, a photovoltaic generator is needed; that is, a set of solar panels are connected in series and/or in parallel to produce the desired direct current. Then, to produce alternating current (at rated voltage $220 \mathrm{~V}$ and rated frequency $50 \mathrm{~Hz}$, for example), a $\mathrm{DC} / \mathrm{AC}$ inverter is required. Thus, photovoltaic inverters are installed between the photovoltaic generator and the point of connection to the grid. Energy transfer from the DC side to the AC side is submitted to various constraints such as secure operating conditions, economical efficiency, and environmental benefits [21,22].

As part of the specific grid-related operation requirements, the PV inverter must also operate within the output voltage and frequency ranges satisfying the tolerated harmonic distortion of the grid voltage wave. From a signal quality point of view, main technical issues to consider in an inverter are in fact power factor and harmonic distortion. The inverter must also have admissible galvanic insolation level between the network and the photovoltaic installation [23-26]. On the other hand, the global efficiency of a grid connected photovoltaic system depends largely on the efficiency of the inverter that in turn depends on circuit topology and control scheme. Generally speaking, this control must ensure various active power operating points at minimum possible reactive power $[27,28]$.

The study realized in this paper is organized as follows. Section 2 deals with the studied energy transfer structure. It gives a general view and a simplified description of main components of this structure. Section 3 details the used mathematical model of solar cells forming the photovoltaic generator. This model is relatively an enhanced one because it includes internal series and parallel resistors and is described by a unique nonlinear equation to solve by iterative numerical process. The first part of Section 4 defines the mathematical model connecting photovoltaic generator to a simple electrical circuit describing the grid bus bar. Then, it presents the steady-state regime and determines useful constraint to ensure the existence of realistic energy transfer solution. The system to solve is also presented and commented. The second part of Section 4 describes the control structure to solve in dynamic regime. The dynamic model of the grid is detailed and the procedure to impose active and reactive powers reference values is outlined. It also introduces how to incorporate corrective terms in voltage reference value. Finally, Section 5 presents and comments on obtained dynamic response signals. The degree of acceptance of the results and their accuracy are also discussed.

\section{Presentation of the Proposed Structure}

The studied structure is shown in Figure 1 and it is composed of the following:

(i) A photovoltaic generator whose voltage and current are denoted, respectively, in the usual way by $V_{p}$ and $I_{p}$. Thus, its output power is

$$
P_{\mathrm{pv}}=V_{p} I_{p}
$$

(ii) A DC/DC push pull voltage converter with a fixed ratio $m$. It is assumed that it delivers a sufficiently smooth and constant voltage $V_{\mathrm{dc}}$ proportional to input voltage $V_{p}$ such that

$$
V_{\mathrm{dc}}=m V_{p} \text {. }
$$

(iii) A DC/AC three-phase inverter considered with a large inductance to sufficiently smooth the current supplied by the high voltage DC side of the DC/DC inverter

(iv) A three-phase voltage source representing the grid (distribution network)

Some working hypotheses are here considered. Surely, the goal is first to facilitate the study. On the other side, we keep in mind that the final target is focused on control feasibility and not to study detailed models of structure components. Thus, we assume that the two power inverters are lossless and alternative current signals are very close to a sinusoidal wave form so that they are treated within the framework of the first harmonic. This hypothesis can be validated by insertion of a filter circuit. Finally, we consider that the input impedance of the grid is very low to ovoid inadmissible voltage drop. In this context, the rms voltage $V$ of the grid is linked to photovoltaic input voltage $V_{p}$ by the following expression where $\rho$ holds for the adjustable duty cycle that varies between 0 and 1 :

$$
\begin{aligned}
& V=\frac{\rho V_{\mathrm{dc}}}{\sqrt{2}}=\frac{m \rho V_{p}}{\sqrt{2}}=\gamma V_{p}, \\
& \gamma=\frac{m \rho}{\sqrt{2}} .
\end{aligned}
$$

\section{PV Array Modelling}

Figure 2 presents the refined model of a PV cell [29-32]. The equivalent electrical circuit is formed by a current source depending on the solar radiation, a diode characterized by a saturation current $I_{0}$ and an idealistic factor $q$, and two resistors modelling the joule losses in the cell $R_{s}$ and $R_{\mathrm{sh}}$, respectively. Current $I_{\mathrm{ph}}$ emitted by the cell under the effect of solar radiation (the current of photons) is strongly related to the intensity of the solar radiation but it depends very slightly on the temperature variation. The current $I_{D}$ of the diode is strongly related to the temperature and to the energy of the gap of the junction. It also depends on the voltage across the diode. The shunt current $I_{\mathrm{sh}}$ corresponds to the current flowing through the shunt resistance $R_{\mathrm{sh}}$ usually considered very high.

Within the meaning of this electrical model given in Figure 2 and the considered notations listed in Abbreviations, we can write the following relations: 


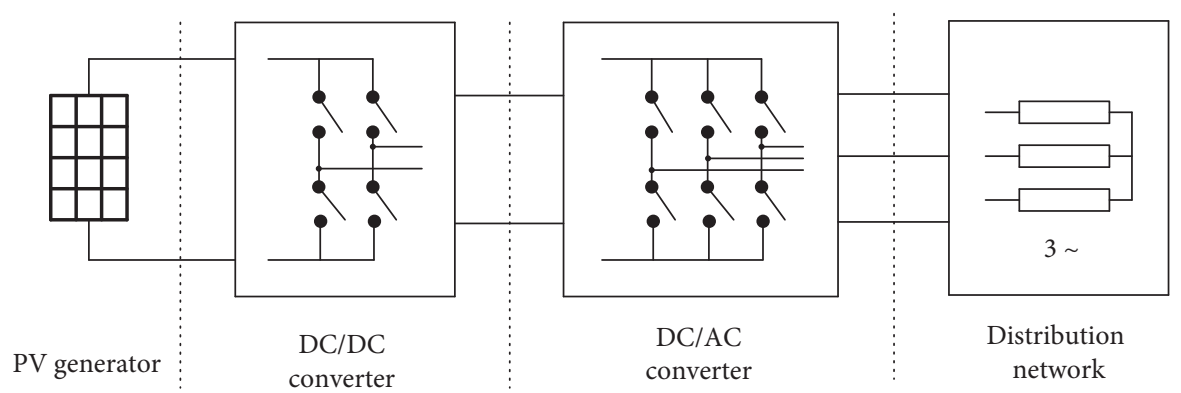

FIgURE 1: The studied energy conversion structure.

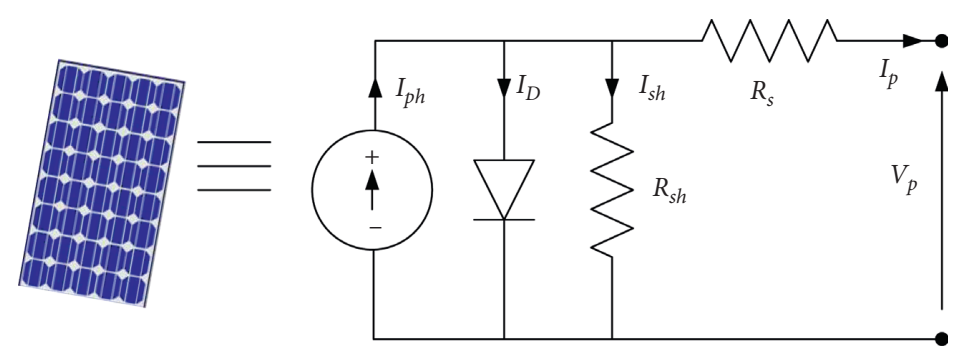

FIgure 2: Electrical model of a solar cell.

$$
\begin{aligned}
I_{\mathrm{ph}} & =I_{D}+I_{p}+I_{\mathrm{sh}}=I_{d}+I_{p}+\frac{V_{p}+R_{s} I_{p}}{R_{\mathrm{sh}}}, \\
I_{D} & =I_{s}\left(\exp \left(\frac{V_{p}+R_{s} I_{p}}{V_{T}}\right)-1\right), \\
V_{T} & =\frac{\mathscr{K}_{I} \mathscr{K}_{B}}{q} T_{j} .
\end{aligned}
$$

The electrical behaviour under load of the solar cell will be described by the following relation:

$$
\begin{gathered}
f\left(I_{p}, I_{p}\right)=I_{p}-I_{\mathrm{ph}}+I_{s}\left(\exp \left(\frac{V_{p}+R_{s} I_{p}}{V_{T}}\right)-1\right) \\
+\frac{V_{p}+R_{s} I_{p}}{R_{\mathrm{sh}}}=0 .
\end{gathered}
$$

This system being nonlinear, we solved it by the iterative Newton-Raphson method which is the most appropriate tool for this case of systems.

\section{Transfer of Photovoltaic Energy to the Grid}

4.1. Study of Transfer Conditions in Steady State. In a general and simplified way, we deal with the circuit of Figure 3 representing a voltage source $v(t)$ supplying a AC load composed by a second voltage source $e(t)$ placed behind an internal impedance. Such a circuit could correspond to a portion of an electrical energy distribution network [33, 34]. The most important thing here is to consider that the shortcircuit power of this load is very important compared to the limit power of the source, that is to say, the conversion chain formed by the photovoltaic generator and the two static

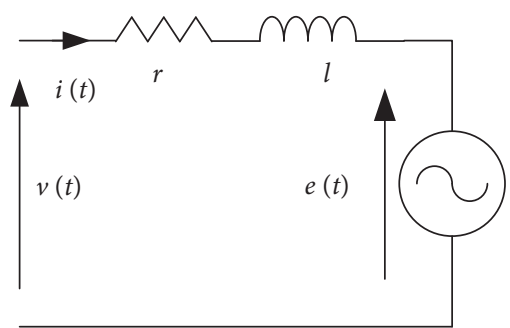

Figure 3: Single-phase equivalent diagram of the studied load.

converters. This assumption makes it possible to consider the voltage source constant in amplitude and frequency whatever the operating point.

During the steady state, Park's vectors merge with Fresnel's ones. Thus, for such a regime, we establish vector diagram of Figure 4 and consequently deduce the relations below. It is to be noted that these equations are generated in a synchronously rotating reference frame associated with voltage vector $\bar{E}$. In this situation, direct and quadrature voltage and current components are noted by capital characters.

$$
\begin{aligned}
& V_{d}=r I_{d}-x I_{q}+E, \\
& V_{q}=r I_{q}+x I_{d} .
\end{aligned}
$$

Moreover, taking into account relation (1) and the power conservation imposed by the assumption of ideal static converters, system (7) is established where $P$ holds for the power delivered by the photovoltaic generator:

$$
\begin{aligned}
& V^{2}=\gamma^{2} V_{p}^{2}=\left(r I_{d}-x I_{q}+E\right)^{2}+\left(r I_{q}+x I_{d}\right)^{2}, \\
& P_{g}=V_{p} I_{p}+r I^{2}=E I_{d}+r\left(I_{d}^{2}+I_{q}^{2}\right) .
\end{aligned}
$$




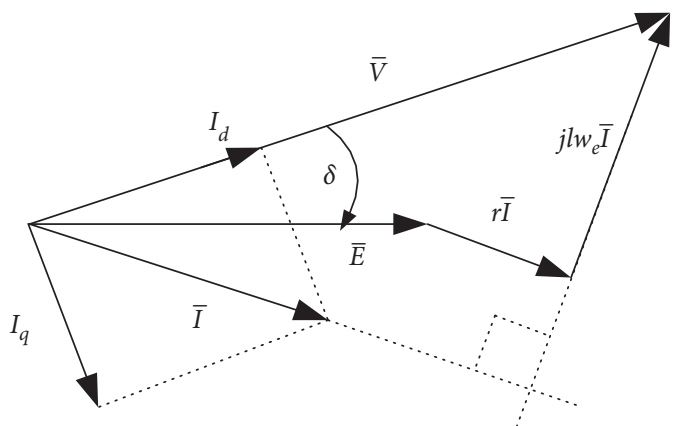

FIgURE 4: Vector diagram of the load in steady state.

For a $\left(V_{p}, I_{p}\right)$ point taken on the $P=f(V)$ curve of the photovoltaic generator and for a specified value of the control variable $\gamma$, the two equations above are sufficient to determine the two variables $I_{d}$ and $I_{q}$ and to deduce from them the values of active power and reactive power at the source bus bar $\bar{E}$ and at the inverter output terminals. At the source bus bar $\bar{E}$, the active power $P$ and the reactive power $Q$ are calculated by

$$
\begin{gathered}
P=E I_{d}, \\
Q=-E I_{q} .
\end{gathered}
$$

The choice of the control value $\gamma$ plays a crucial role in the existence of a solution; this is on one hand, and on the other hand, it plays a crucial role in the degree of satisfaction with the solution if it exists. In fact, we could find a solution which would correspond, for example, to an inadmissible balance in reactive power and in this case the selected value is rejected. When the photovoltaic generator works in current generator mode, that is to say, when its voltage is low, the voltage at the output of the inverter would also be low and the load would be called upon to supply reactive power to the conversion chain. This is of course an undesirable regime on several levels: current overload, drop in voltage, and active power.

The strategies largely preferred in the field of integrating photovoltaic energy into the network consist in imposing zero reactive power on the bus bar of this network. It is precisely this type of control that we are interested in, in this study. A control structure is developed to impose a reference active power value $P_{\text {ref }}$, which is as high as possible, and a zero reference reactive power $Q_{\text {ref }}$ at the point where the source $E$ representing the electrical network is located. According to (8), to obtain null reactive power at the input of the electrical network, the quadrature component $I_{q}$ of the current must also be zero. So, by imposing this condition in (7)-(9), we obtain

$$
\begin{aligned}
\gamma^{2} V_{p}^{2} & =z^{2} I_{d}^{2}+2 r E I_{d}-2 x I_{q} E+E^{2}, \\
P_{g} & =V_{p} I_{p}=E I_{d}+r I_{d}^{2} .
\end{aligned}
$$

By multiplying (10) by $\left(r / z^{2}\right)$ and subtracting (11), we get

$$
I_{d}=\frac{z^{2} V_{p} I_{p}-r\left(\gamma^{2} V_{p}^{2}-E^{2}\right)}{\left(x^{2}-r^{2}\right) E} .
$$

Then, by combining (11) and (12) and thus eliminating the current component $I_{d}$, one obtains the following unique equation:

$$
\begin{aligned}
\left(x^{2}-r^{2}\right)^{2} P_{g}= & \left(x^{2}-r^{2}\right)\left[z^{2} P_{g}-r\left(\gamma^{2} V_{p}^{2}-E^{2}\right)\right] \\
& +\frac{r}{E^{2}}\left[z^{2} P_{g}-r\left(\gamma^{2} V_{p}^{2}-E^{2}\right)\right]^{2} .
\end{aligned}
$$

For a set of parameters $(r, x, E)$ chosen suitably, this equation defines in the plane $\left(V_{p}, P_{g}\right)$ a curve branch which could cut the characteristic of the photovoltaic generator at a certain operating point as illustrated in Figure 5.

If we place at the point of the no-load regime, that is to say, $V_{p}=V_{\text {oc }}$ and $P=Q=0$, the preceding equation implies the trivial solution:

$$
\gamma V_{p}=\gamma V_{\text {oc }}=E \text {. }
$$

It follows that the minimum theoretical value of $\gamma$ guaranteeing the existence of an operating point of the photovoltaic generator for the climatic working conditions is

$$
\gamma_{\min }=\frac{E}{V_{\mathrm{oc}}} \text {. }
$$

Any voltage ratio inferior to this critical value makes it impossible to transfer active power to the source $E$ while respecting the zero reactive power. However, it is obvious that the best choice of $\gamma$ is the one allowing the transfer of the maximum power. Let us say, for example, that we are at the optimum operating point of the photovoltaic generator where voltage, current, and power are, respectively, $V_{m}, I_{m}$, and $P_{m}$. From (10), we can calculate the value of the direct current $I_{d}$ and deduce the optimum power. Substituting the result found in (10) allows us to deduce the value of the control variable $\gamma$ to be used. If the short-circuit impedance of the network is low enough, which is usually the case, this value would almost correspond to the optimal value:

$$
\gamma_{m}=\frac{E}{V_{m}} \text {. }
$$

As the global voltage ratio includes the turns ratio $m$ of the push pull transformer, it is evident that the feasibility condition (15) turns into a constraint on $m$. This means that a particular attention must then be given to the sizing of the minimum value of the DC/DC inverter. If such a precaution is not taken into account, the duty cycle of the inverter checking the operating point would be greater than 1 and the control structure would also fail because this ratio is of course saturated at 1 . From this we understand that it is important to carry out a preliminary scan taking into account the limiting climatic variations in order to decide on the minimum value of the $\mathrm{DC} / \mathrm{DC}$ converter ratio $\mathrm{m}$. In a formal way, we pose the constraint below where $\gamma_{c}$ is a value verifying the transfer of the optimal power within the largest variation in climatic conditions: 


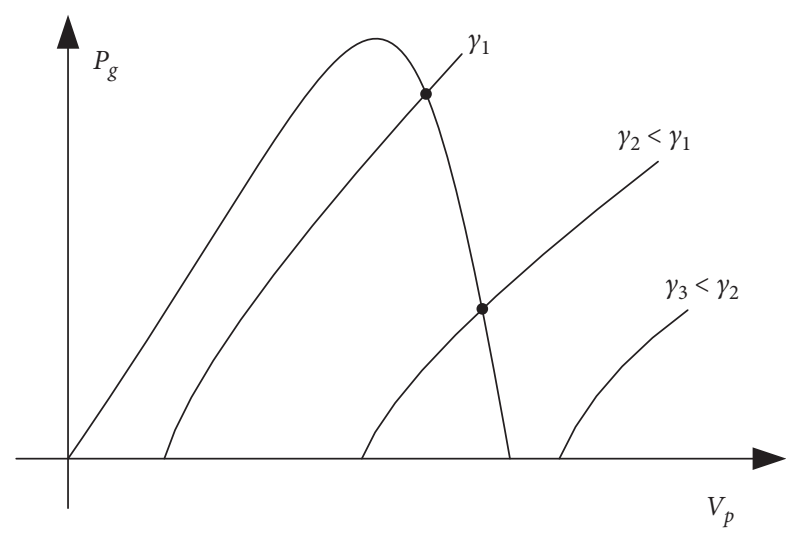

FIGURE 5: Zero reactive power control solutions.

$$
m>\sqrt{2} \gamma_{c} .
$$

The consideration of grid parameters $(r, x, E)$ in the analysis of the possibilities of integrating photovoltaic energy is an aspect of great importance. To be able to transfer the power available in the photovoltaic source to the grid, it is essential to know in advance the limit level of this power and to check the effective possibility of transferring it. By this we mean that a preliminary calculation of the transmissible power is very necessary to ensure the transfer properly. In the case, for example, where the capacity for transferring power to the network is less than the power to be transferred, the control structure would regain certain failure. In terms of the power limit, and therefore in terms of the existence of a transfer solution, the following condition must be respected:

$$
P<\frac{E^{2}}{2(z-r)}-r I^{2} .
$$

Finally, the operating point corresponds to the simultaneous resolution of the three equations of the system (19) below by the Newton-Raphson method in terms of the three variables $V_{p}, I_{p}$, and $I_{d}$, for a specified value of $\gamma$. The details of this method are given in Figure 6. From the obtained value of $I_{d}$, one easily deduces the value of the power $P$ transmitted to the source $E$ of the network.

$$
\left\{\begin{array}{l}
I_{p}-I_{\mathrm{ph}}+I_{s}\left(\exp \left(\frac{V_{p}+R_{s} I_{p}}{V_{T}}\right)-1\right)+G_{\mathrm{sh}}\left(V_{p}+R_{s} I_{p}\right)=0, \\
z^{2} I_{d}^{2}+2 r E I_{d}+E^{2}-\gamma^{2} V_{p}^{2}=0, \\
E I_{d}+r I_{d}^{2}-V_{p} I_{p}=0 .
\end{array}\right.
$$

4.2. Control Structure in Dynamic Regime. It is important to show the feasibility of the problem in variable regime through a control strategy. This is where the objective of this section lies. To approach this problem in the simplest and clearest way possible, only the dynamics of the control loop of the inverter and that of the load are here taken into account. It is assumed that the dynamics of the DC/DC converter upstream of the inverter is relatively slow because of its output large filter capacitor.

The proposed control structure is indicated by Figure 7 . This structure comprises a set of modules associated with the necessary mathematical models. Module 1 relates to the photovoltaic generator. Its inputs are the variables illustrating the climatic conditions: ambient temperature $T_{a}$ and solar radiation $E_{s}$. Its outputs are current $I_{p}$ and voltage $V_{p}$ which depend on the power level of the load and input variables $T_{a}$ and $E_{s}$. Module 2 represents the DC/DC push pull converter, its output voltage is linked to photovoltaic generator voltage by equation (2). Module 3 generates reference voltage $\bar{v}_{\text {ref }}$ vector with a module $\rho_{\text {ref }}$ and phase $\delta_{\text {ref }}$ with respect to the grid synchronous angle. These two quantities come from module 7 where the control part resides. Module 4 realises space pulse width modulation (SPWM) signals corresponding to switching times of power transistor of the inverter schematised by module 5. Output signals of this module are two quadratic voltage components in Concordia's representation. Module 6 solves the differential equation (20) below written in the stationary Concordia's reference frame. When they appear, Concordia's voltage and current components are noted with small characters. Relation (21) is to consider that the voltage at grid bus bar is purely sinusoidal.

$$
\begin{aligned}
\frac{\mathrm{d} \bar{i}}{\mathrm{~d} t} & =\frac{\bar{v}-r \bar{i}-\bar{e}}{\ell}, \\
\bar{e} & =E \exp (j \omega t) .
\end{aligned}
$$

In Park's rotating reference frame synchronized with the network voltage source $\bar{E}$, the dynamics of the components of the current transmitted is expressed by

$$
\begin{aligned}
& \frac{\mathrm{d} I_{d}}{\mathrm{~d} t}=\frac{V_{d}-E-r I_{d}+x I_{q}}{\ell}, \\
& \frac{\mathrm{d} I_{q}}{\mathrm{~d} t}=\frac{V_{q}-r I_{q}-x I_{d}}{\ell} .
\end{aligned}
$$

These current components must converge in steady state towards their reference values imposed by the required active power $P_{\text {ref }}$ and reactive power $Q_{\text {ref }}$ :

$$
\begin{aligned}
& I_{\text {dref }}=\frac{P_{\text {ref }}}{E}, \\
& I_{\text {qref }}=\frac{Q_{\text {ref }}}{E}=0 .
\end{aligned}
$$

The output voltage components of the inverter are also known in steady state:

$$
\begin{aligned}
& V_{\text {dref }}=E+r I_{\mathrm{dref}}, \\
& V_{\text {qref }}=x I_{\mathrm{dref}} .
\end{aligned}
$$

For the transient state, one uses these relations to introduce corrective terms compensating the effect of the dynamic variation of the current components. The added 


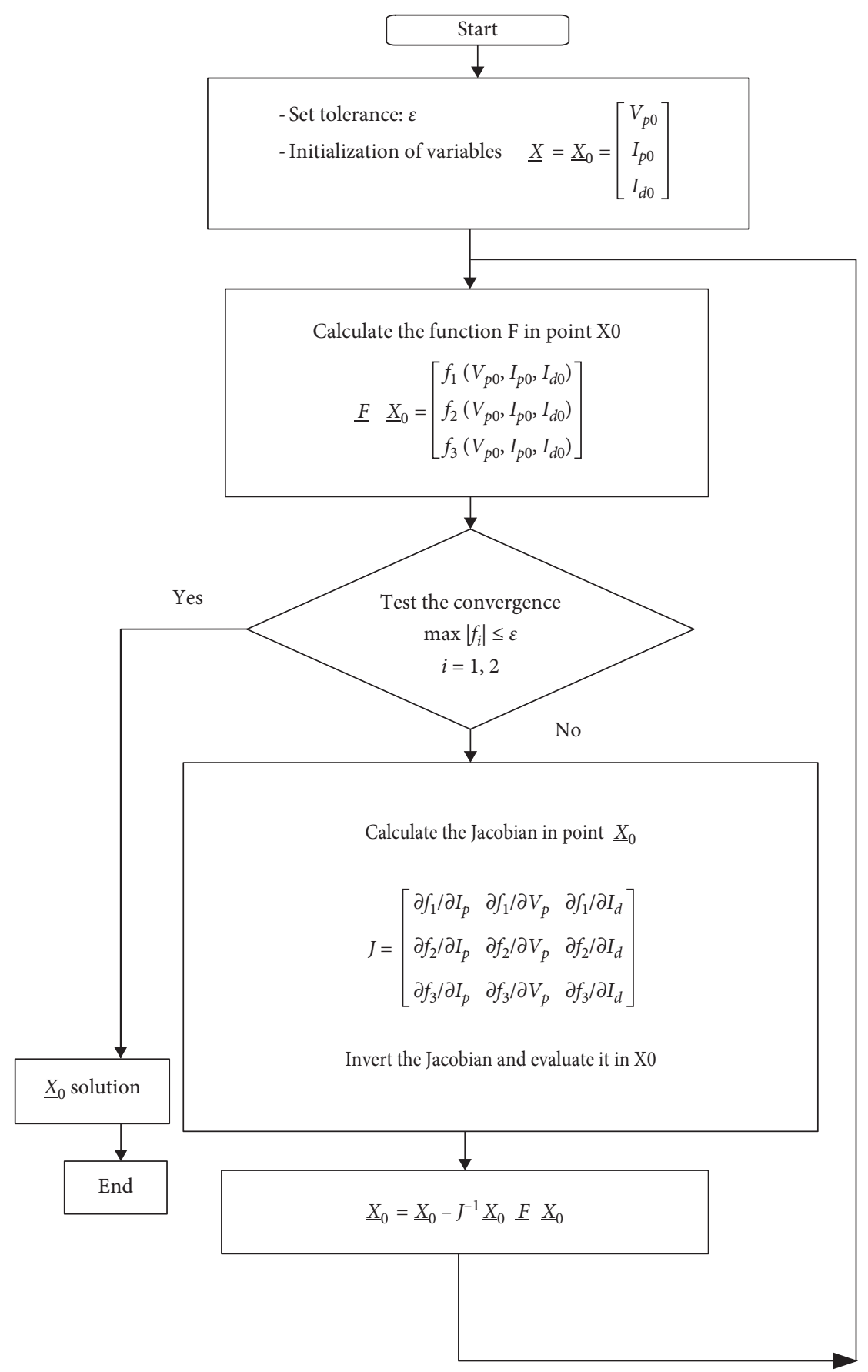

FIgURE 6: Chart diagram of Newton-Raphson method.

corrective terms are as follows, where $r_{c}$ is a constant whose value will be provided in the part reserved for the simulation:

$$
\begin{aligned}
& \Delta V_{\text {dref }}=r_{c}\left(I_{\text {dref }}-I_{d}\right), \\
& \Delta V_{\text {qref }}=-r_{c} I_{q} .
\end{aligned}
$$

We then consider a reference voltage such as

$$
\begin{aligned}
& V_{\text {dref }}=E+r I_{\text {dref }}+r_{c}\left(I_{\mathrm{dref}}-I_{d}\right), \\
& V_{\text {qref }}=x I_{\text {dref }}-r_{c} I_{q} .
\end{aligned}
$$

This fully defines the inputs of the inverter control module which are the voltage duty cycle $\rho_{\text {ref }}$ and its phase $\delta_{\text {ref }}$ in the grid synchronous frame:

$$
\begin{aligned}
& \rho_{\text {ref }}=\frac{\sqrt{2\left(V_{\mathrm{dref}}^{2}+V_{\mathrm{qref}}^{2}\right)}}{m V_{p}}, \\
& \delta_{\mathrm{ref}}=t_{g}^{-1}\left(\frac{V_{\mathrm{qref}}}{V_{\mathrm{dref}}}\right) .
\end{aligned}
$$




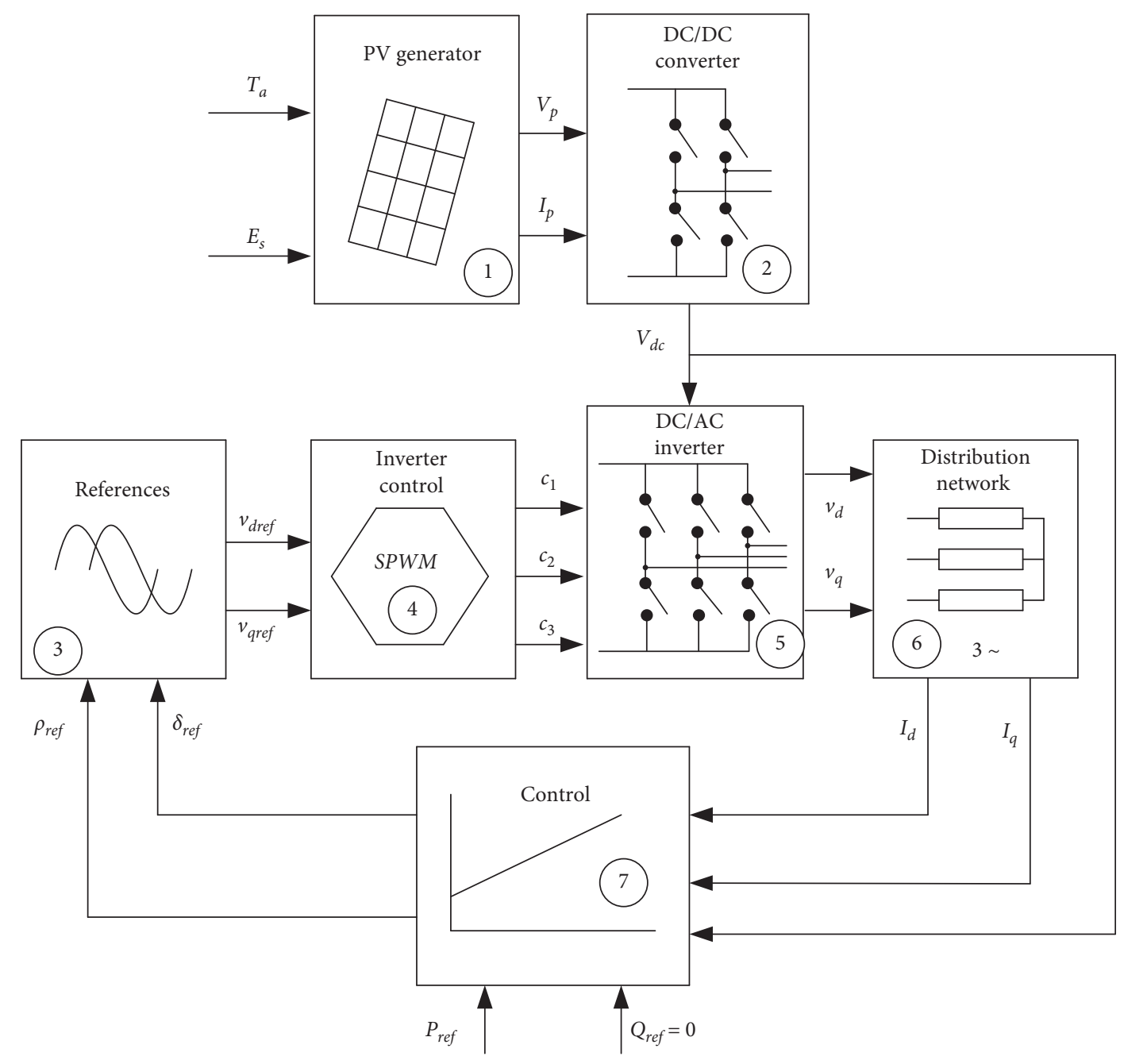

Figure 7: The developed control structure.

\section{Simulations and Results}

To check the performance of the proposed command in dynamic regime, a MATLAB/Simulink model of the PV system was initially developed. The parameters to be used are inspired from a practical project now under development in our research laboratory ERCO (Energy, Robotics, Control and Optimisation) situated at INSAT, Tunis.

The photovoltaic generator has been described in a previous work [31]. It is formed by 10 solar panels referenced TITAN STP-12-50, Multi-Cristallin technology. Table 1 reports the necessary parameters at standard climatic conditions.

The DC/DC inverter is a part of a real camping power supply. The reference of this device is KEBO IPS 1200. It is a rated $12 \mathrm{~V} / 240$ volts and a rated $500 \mathrm{~W}$ power device. This inverter is designed to be connected to a car battery of 12 volts. To meet this voltage constraint, solar panels are connected in parallel. In addition, the DC/DC inverter has being modified in our laboratory so that some input chemical capacitors support $25 \mathrm{dc}$ volts. At a very low load, close to open circuit, we have verified that the voltage ratio is $m=22.2$.
The global structure given by Figure 7 is simulated under the following conditions:

(i) Climatic conditions: temperature $T_{a}=25^{\circ} \mathrm{C}$ and a solar radiation $E_{s}=1000 \mathrm{~W} / \mathrm{m}^{2}$

(ii) Push-pull converter with fixed ratio: $m=22.2$

(iii) PWM frequency: $5 \mathrm{kHz}$

(iv) Reference reactive power $Q_{\text {ref }}=0$

(v) Reference active power $P_{\text {ref }}=408 \mathrm{~W}$ : this equals $97 \%$ of the maximum power of the photovoltaic generator

(vi) Filtering period: $m=200 \mu \mathrm{s}$

(vii) Grid parameters: $r=1 \Omega, x=5 \Omega$

Figures 8 and 9 show the structure dynamic response in terms of active power and reactive power control. These variables suitably converge towards the requested references in a sufficiently short response time. Active power convergence is good. However, reactive power oscillates around zero. This is due to the fact that the internal impedance of the source representing the network is low, which generates a phenomenon of permanent current ripple around its 
Table 1: Parameters of the PV generator used in simulation.

\begin{tabular}{lcc}
\hline & $\begin{array}{c}\text { Solar panel TITAN-12-50 } \\
\text { cell type: EFG Multi-Cristallin }\end{array}$ & 36 \\
\hline Number of series cells: ns & & 10 \\
Number of parallel PV arrays: Np & & 1 \\
Number of series PV arrays: Ns & $21 \mathrm{~V}$ \\
Open circuit voltage in STC (per one PV array) & $3.2 \mathrm{~A}$ \\
Short-circuit current en STC (per one PV array) & $17.2 \mathrm{~V}$ \\
Optimal voltage in STC (per one PV array) & $2.9 \mathrm{~A}$ \\
Optimal current in STC (per one PV array) & $45 \mathrm{~W}$ per module \\
Optimal power in STC & $25^{\circ} \mathrm{C}$ \\
Temperature & $1000 \mathrm{~W} / \mathrm{m}^{2}$ \\
Radiation & & 10 \\
\hline
\end{tabular}

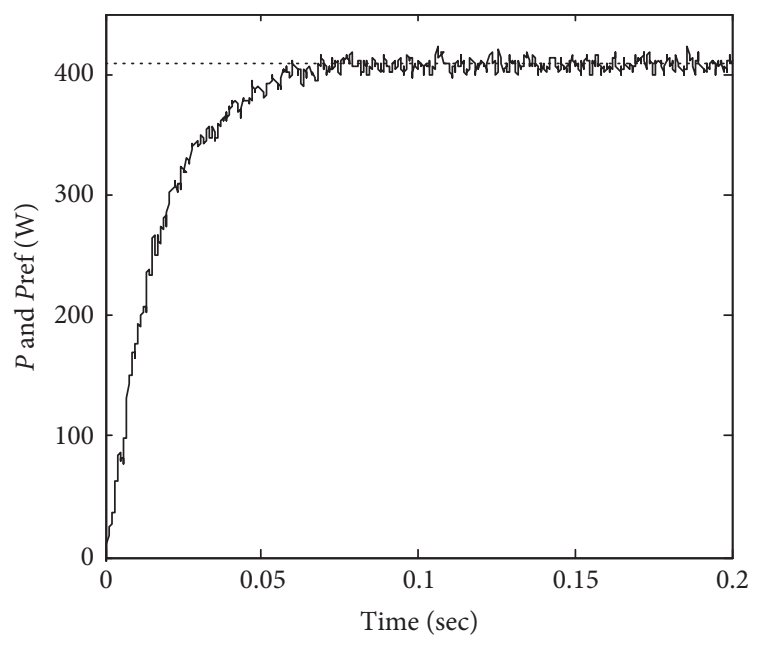

Figure 8: Dynamic evolution of active power.

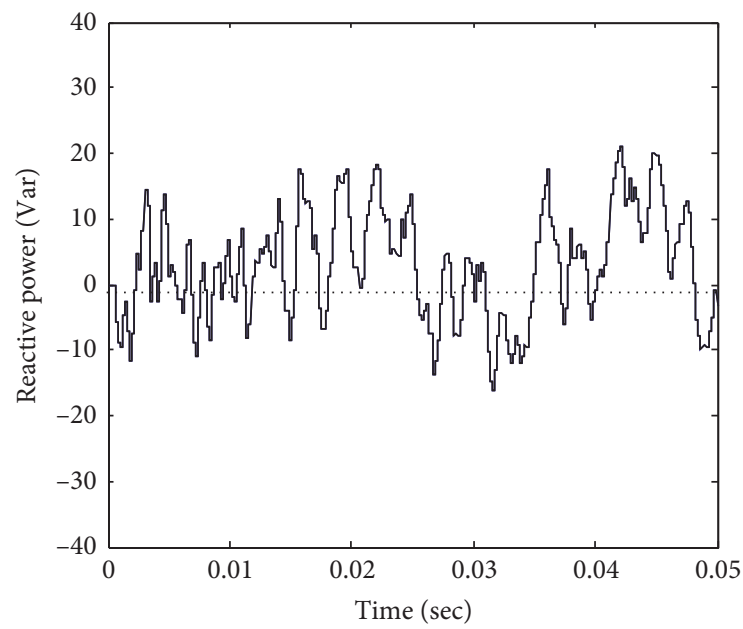

FIgURe 9: Dynamic evolution of reactive power.

fundamental sinusoidal component. We can easily observe that absolute reactive power variation remains within 20 vars that is inferior to $10 \%$ of final active power value. In general point of view, this performance gives full satisfaction. In theoretical point of view, oscillations can be justified by the fact that the reference voltage is defined in a pseudostatic form on one hand and the value of the compensation resistor $r_{c}$ is sufficiently large on the other hand.

Figure 10 shows the evolution of the control variable $\gamma$ which is proportional to the duty cycle of the inverter. We can easily see that this value remains within the range specified by the steady-state study. In fact, it converges to a value around $\gamma \simeq 15$ which means that the voltage ratio is about $\rho \simeq 95 \%$.

The phase shift of the voltage of the inverter with respect to the synchronous axis of the network is of the order of $\delta=2.5^{\circ}$ in steady state as indicated by Figure 11. This value, which seems very low, is well justified. The maximum power that can be transmitted to the network is inversely proportional to its internal impedance; see expression (27). This power is here very large as compared to the power requested.

Figure 12 gives a zoom on the instantaneous waveform of the current. Although the average value of the current remains generally sinusoidal, we observe the chopping due to the sudden switching of the output voltage of the inverter. Surely, this waveform is not of sufficient degree of acceptance. But we are also sure that the result can be enhanced. Three factors can contribute to reaching this goal. In fact, adding a filter circuit, realising accurate calculation of the transfer impedance, and finding optimal switching frequency could be a real solution.

Figure 13 gives a zoom on the steady state of the voltage signals. The central curve of this figure indicates the instantaneous average value which naturally characterizes the reference voltage. Figures 14 and 15 correspond, respectively, to the evolution of the current and the voltage of the photovoltaic generator. We can also prove through these curves the convergence of the power delivered towards the requested reference.

We have previously shown that is possible to obtain a steady-state operating point characterized by an active power $P_{\text {ref }}=408 \mathrm{~W}$ and null reactive power with a global voltage ratio of $\gamma \simeq 15$. Imposing $\gamma=12$ in an open loop simulation case leads to inadmissible oscillations and shows impossibility to transfer the requested power. This result is summarised in Figures 16 and 17. 


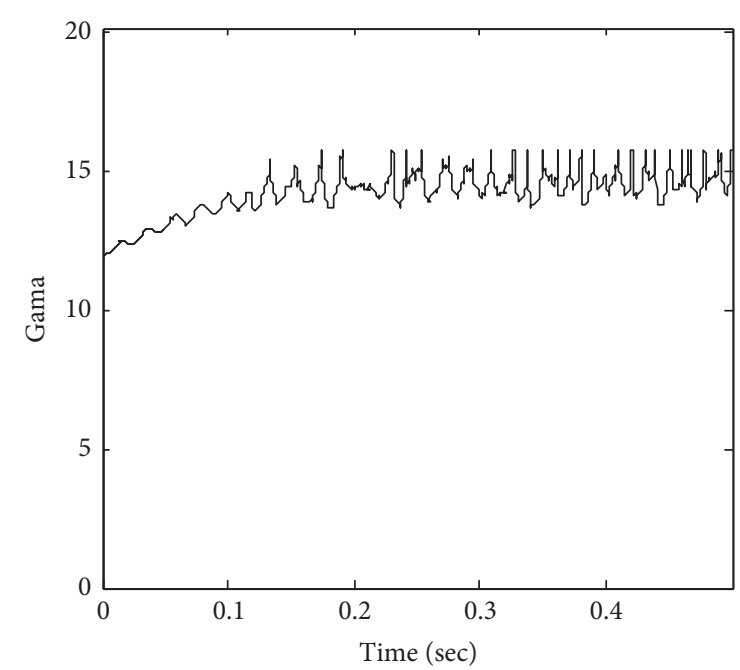

FIgURE 10: Evolution of the variable control $\gamma$.

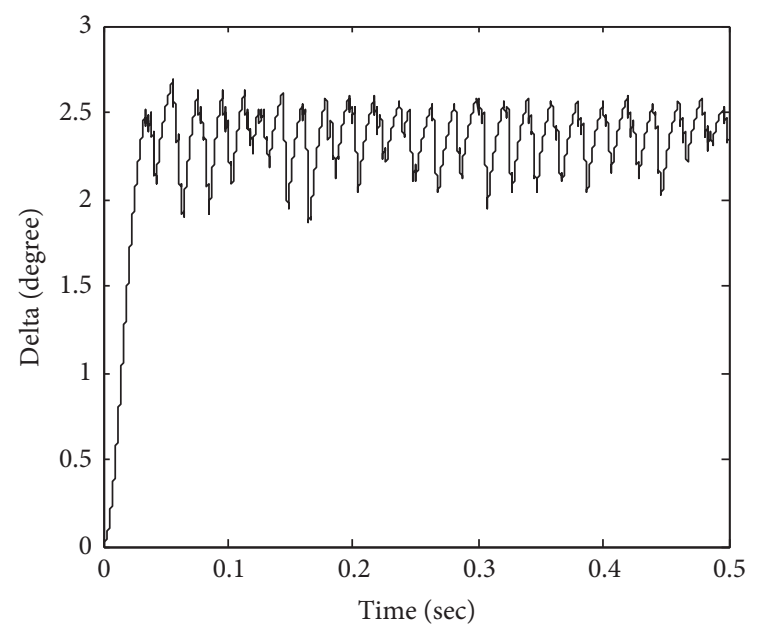

Figure 11: Dynamic evolution of the angle $\delta$.

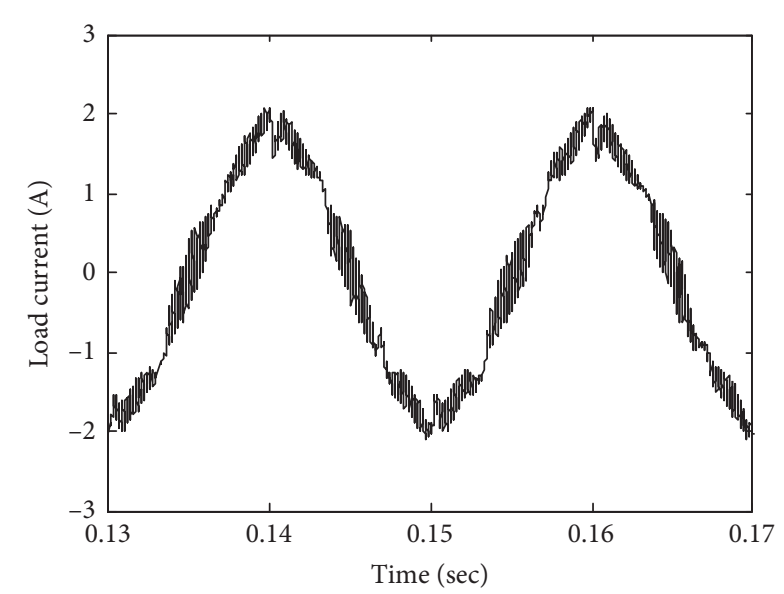

Figure 12: The steady state of the load current.

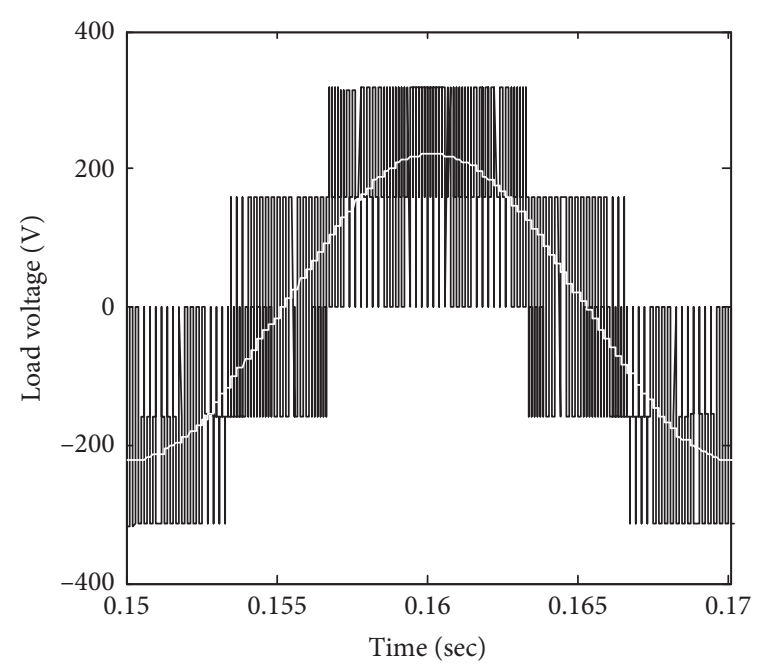

Figure 13: The steady state of the load voltage.

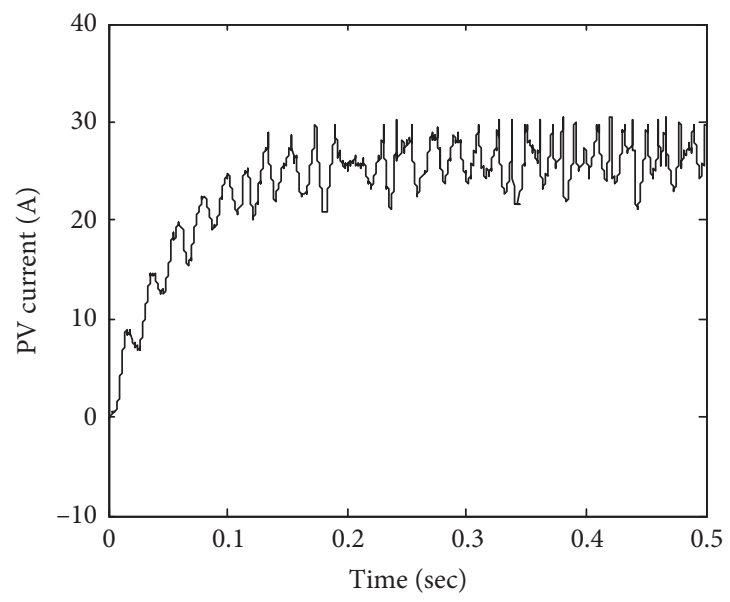

FIgURE 14: The steady state of the load current.

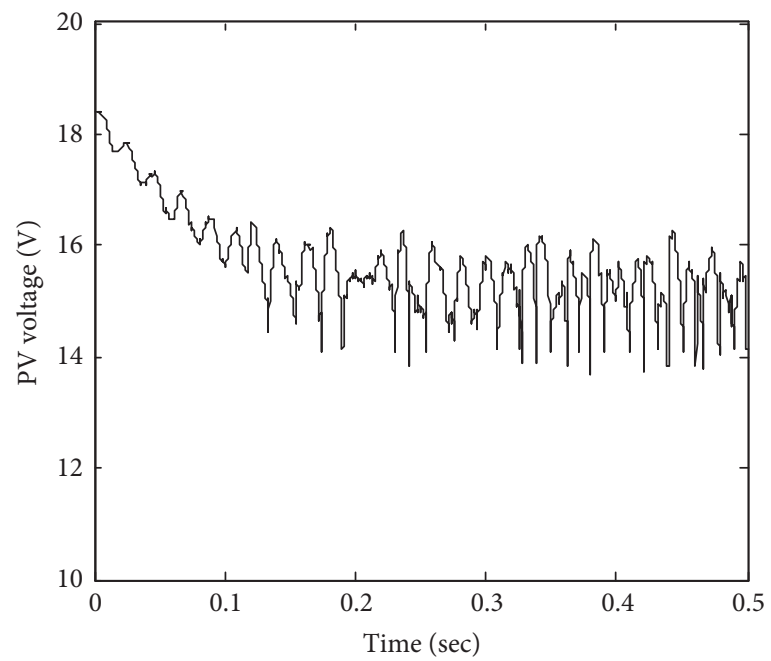

FIgURE 15: Evolution of the voltage of the photovoltaic generator. 


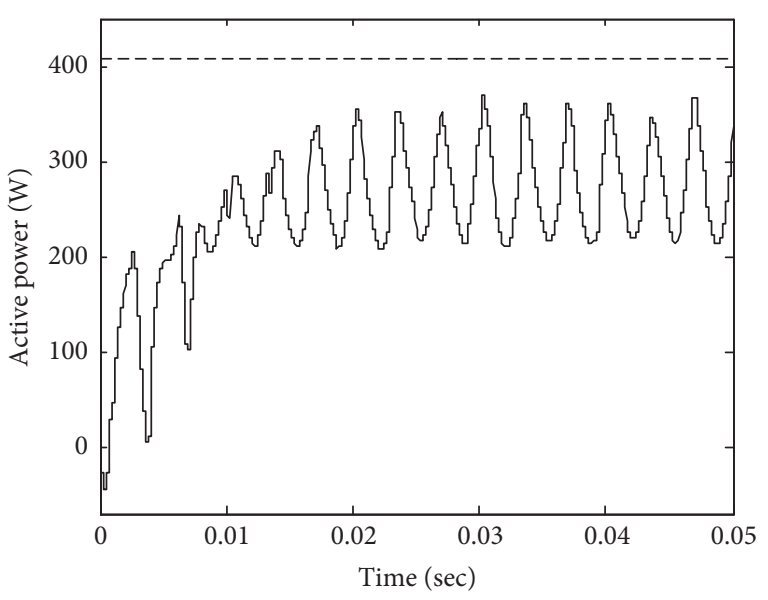

Figure 16: Dynamic evolution of the active power for $\gamma=12$.

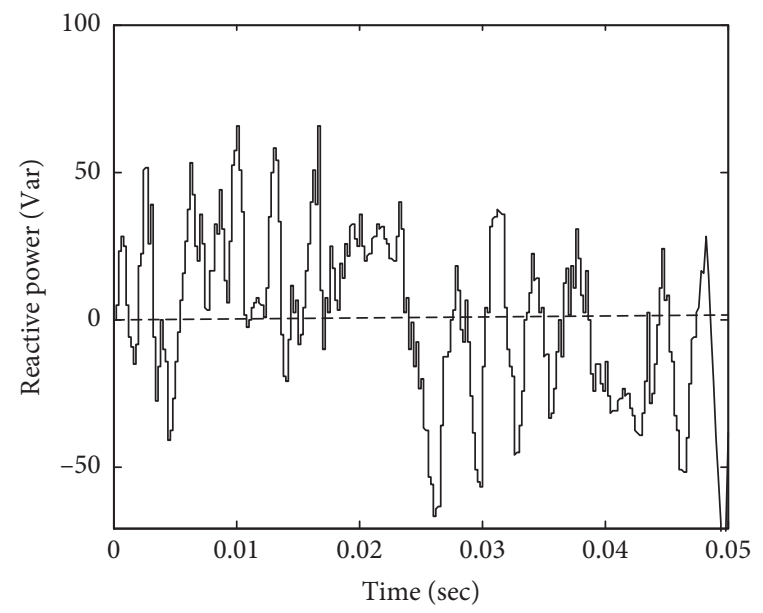

Figure 17: Dynamic evolution of the reactive power for $\gamma=12$.

\section{Conclusion}

The aim of this analysis was to show the feasibility of transferring photovoltaic energy to the electrical grid with control of active and reactive powers. The proposed structure is based on a push-pull converter connected to threephase AC-DC inverter. The steady-state study of the structure in question showed the limits of the energy transfer. Indeed, for a point $\left(V_{p}, I_{p}\right)$ considered on the characteristic of the photovoltaic generator and for a specified value of the control variable $\gamma$, we can deduce the value of the active power and of the reactive power both at the level of the alternative current bus bar and at the output terminals of the inverter.

The choice of the value of $\gamma$ plays a crucial role on one hand in the existence of a solution and on the other hand in the degree of satisfaction of the solution if it exists. Indeed, one could find a solution which would correspond, for example, to an inadmissible balance in reactive power. When the photovoltaic generator works in current generator mode, the voltage at the output of the inverter would also be low and the load would be called upon to supply reactive power to the conversion chain. This is obviously an undesirable regime on many levels: current overload, drop in voltage and active power, and being very profitable on the network side of the distribution. On the contrary, when the photovoltaic generator works in voltage generator mode, with the contribution of the adjustment on the converter side, we could have an output voltage greater than the voltage $E$ of the network. In such a case, the conversion chain would produce reactive power. The mathematical model of the whole system with a three nonlinear equations describing the behaviour in static mode was formulated. The method of Newton-Raphson was used in order to solve this system numerically. The last point addressed in this work is the study of the dynamic regime during energy transfer. The command developed aims to ensure the transfer of maximum active power and zero reactive power. We have detailed the control strategy adopted; simulations in dynamic regime have shown the effectiveness of the control law.

\author{
Abbreviations \\ $E_{e}: \quad$ Solar radiation $\left(\mathrm{W} / \mathrm{m}^{2}\right)$ \\ $T_{j}:$ Temperature of diode junction $\left(K^{\circ}\right)$ \\ $\omega_{g}$ : Energy gap of the junction $(\mathrm{ev})$ \\ $q: \quad$ Electronic charge $(1.610-13 C)$ \\ $\mathscr{K}_{B}$ : Boltzmann's constant $\left(J / K^{\circ}\right)$ \\ $\mathscr{K}_{I}$ : Diode quality factor \\ $R_{s}:$ Series resistor $(\Omega)$ \\ $R_{\mathrm{sh}}$ : Shunt resistor $(\Omega)$ \\ $I_{\mathrm{cc}}$ : Short-circuit current $(A)$ \\ $I_{\mathrm{ph}}$ : Photo current diode $(A)$ \\ $I_{s}$ : $\quad$ Saturation current diode $(A)$ \\ $T_{a}:$ Ambient temperature $\left({ }^{\circ} \mathrm{C}\right)$ \\ $V_{T}$ : Thermal voltage of the diode $(V)$ \\ $V_{\text {co }}$ : Open circuit voltage $(V)$.
}

\section{Data Availability}

The parameters of the photovoltaic panel used to support the findings of this study are included within the article.

\section{Conflicts of Interest}

The authors declare that they have no conflicts of interest.

\section{References}

[1] N. Kittner, F. Lill, and D. M. Kammen, "Energy storage deployment and innovation for the clean energy transition," Nature Energy, vol. 2, no. 9, Article ID 17125, 2017.

[2] M. Xiao, J. Tobias, J. Haas, and M. Klein, "Plummeting costs of renewables-are energy scenarios lagging?" Energy Strategy Reviews, vol. 35, Article ID 100636, 2021.

[3] S. Teske, S. Sawyer, O. Schaefer, T. Pregger, S. Simon, and T. Naegler, "Energy," Evolution-A Sustainable World Energy Outlook 2015, Greenpeace International, Amsterdam, Netherlands, 2015.

[4] K. Branker, M. J. M. Pathak, and J. M. Pearce, "A review of solar photovoltaic levelized cost of electricity," Renewable and Sustainable Energy Reviews, vol. 15, no. 9, pp. 4470-4482, 2011. 
[5] M. Ram, D. Bogdanov, A. Aghahosseini et al., Global Energy System Based on 100\% Renewable Energy-Power, Heat, Transport and Desalination Sectors, Lappeenranta University of Technology, Energy Watch Group, Berlin, Germany, 2019.

[6] J. Page, The Role of Solar-Radiation Climatology in the Design of Photovoltaic Systems' Part II-1-A, McEvoy's Handbook of Photovoltaics', Elsevier Academic Press, Cambridge, MA, USA, 3rd edition, 2018.

[7] D. Yang, H. Latchman, D. Tingling, and A. A. Amarsingh, "Design and return on investment analysis of residential solar photovoltaic systems," IEEE Potentials, vol. 34, no. 4, pp. 11-17, 2015.

[8] S. K. Yadav and U. Bajpai, "Performance evaluation of a rooftop solar photovoltaic power plant in northern India," Energy for Sustainable Development, vol. 43, pp. 130-138, 2018.

[9] A. K. Akella, M. P. Sharma, and R. P. Saini, "Optimum utilization of renewable energy sources in a remote area," Renewable and Sustainable Energy Reviews, vol. 11, no. 5, pp. 894-908, 2007.

[10] R. Ramakumar, "Energizing rural areas of development countries using IRES," in Proceedings of the 31st Intersociety Energy Conversion Engineering Conference, vol. 3, pp. 15361541, Washington, DC, USA, August 1996.

[11] A. Y. Saber and G. K. Venayagamoorthy, "Efficient utilization of renewable energy sources by gridable vehicles in cyberphysical energy systems," IEEE Systems Journal, vol. 4, no. 3, pp. 285-294, 2010.

[12] J. Tomic and W. Kempton, "Using fleets of electric-drive vehicles for grid support," Journal of Power Sources, vol. 168, no. 2, pp. 459-468, 2007.

[13] V. K. Sood and H. Abdelgawad, "Power converter solutions and controls for green energy," in Distributed Energy Resources in Microgrids, R. K. Chauhan and K. Chauhan, Eds., Academic Press, Cambridge, MA, USA, 2019.

[14] E. S. N. Raju and T. Jain, "Chapter 2-distributed energy resources and control," in Distributed Energy Resources in Microgrids, R. K. Chauhan and K. Chauhan, Eds., Academic Press, Cambridge, MA, USA, 2019.

[15] Academic Press, Energy, Academic Press, Cambridge, MA, USA, 2014.

[16] O. S. Ohunakin, "Energy utilization and renewable energy sources in Nigeria," Journal of Engineering and Applied Sciences, vol. 5, no. 2, pp. 171-177, 2010.

[17] T. Adefarati and R. C. Bansal, "Chapter 2-energizing renewable energy systems and distribution Generation," in Pathways to a Smarter Power System, A. Taşc1karaoğlu and O. Erdinç, Eds., Academic Press, Cambridge, MA, USA, 2019.

[18] B. Brand and K. Blok, "Renewable energy perspectives for the North African electricity systems: a comparative analysis of model-based scenario studies," Energy Strategy Reviews, vol. 6, pp. 1-11, 2015.

[19] NEPCO, Annual Report 2012, National Electric Power Company (NEPCO), Amman, Jordan, 2012.

[20] IEA, Energy Balances of Non-OECD Countries, International Energy Agency, Paris, France, 2012 edition, 2013.

[21] E. Roman, R. Alonso, P. Ibanez, S. Elorduizapatarietxe, and D. Goitia, "Intelligent PV module for grid-connected PV systems," IEEE Transactions on Industrial Electronics, vol. 53, no. 4, pp. 1066-1073, 2006.

[22] A. Q. Al-Shetwi, M. A. Hannan, K. P. Jern, A. A. Alkahtani, and A. E. Abas, "Power quality assessment of grid-connected $\mathrm{PV}$ system in compliance with the recent integration requirements," Electronics, vol. 9, no. 2, p. 366, 2020.
[23] J. Nömm, S. Rönnberg, and M. Bollen, “An analysis of voltage quality in a nanogrid during islanded operation," Energies, vol. 12, no. 4, p. 614, 2019.

[24] S. Y. Mousazadeh Mousavi, A. Jalilian, M. Savaghebi, and J. Guerrero, "Flexible compensation of voltage and current unbalance and harmonics in microgrids," Energies, vol. 10, no. 10, p. 1568, 2017.

[25] B. Fan, J. Peng, J. Duan, Q. Yang, and W. Liu, "Distributed control of multiple-bus microgrid with paralleled distributed generators," IEEE/CAA Journal of Automatica Sinica, vol. 6, no. 3, pp. 676-684, 2019.

[26] B. Ali, B. Mohamed Lokmane, and D. Mohamed, "Grid connected photovoltaic system, for a 800 W," Energy Procedia, vol. 74, pp. 414-422, 2015.

[27] S. Chatterjee, P. Kumar, and S. Chatterjee, "A techno-commercial review on grid connected photovoltaic system," Renewable and Sustainable Energy Reviews, vol. 81, pp. 2371-2397, 2018.

[28] A. Amir, A. Amir, H. S. Che, A. Elkhateb, and N. A. Rahim, "Comparative analysis of high voltage gain DC-DC converter topologies for photovoltaic systems," Renewable Energy, vol. 136, pp. 1147-1163, 2019.

[29] M. M. Fouad, L. A. Shihata, and E. I. Morgan, “An integrated review of factors influencing the performance of photovoltaic panels," Renewable and Sustainable Energy Reviews, vol. 80, pp. 1499-1511, 2017.

[30] H. Brahmi and R. Dhifaoui, "Dynamic characteristics and improved MPPT control of PV generator," Frontiers in Energy, vol. 7, no. 3, pp. 342-350, 2013.

[31] G. M. Tina and S. Scrofani, "Electrical and thermal model for PV module temperature evaluation," in Proceedings of the 14th IEEE Mediterranean Electrotechnical Conference, pp. 585-590, Ajaccio, France, May 2008.

[32] R. Gammoudi, H. Brahmi, and R. Dhifaoui, "Estimation of climatic parameters of a PV system based on gradient method," Complexity, vol. 2019, Article ID 7385927, 10 pages, 2019.

[33] H. Brahmi and D. Rachid, "On UPFC application in interconnected power system including wind energy," in Proceedings of the ICESE 2011: International Conference on Energy Systems Engineering, Venice, Italy, April 2011.

[34] H. Brahmi, H. Othman, and D. Rachid, "Direct voltage stability assessment of large power systems," in Proceedings of the 6ème Conférence Internationale des Sciences et Techniques de l'Automatique STA'05, Sousse, Tunisie, December 2005. 